\title{
Expert testimony in court. 1: General principles
}

\author{
Patricia Casey
}

Abstract Since the Woolf reforms were incorporated into legal practice in civil cases in England and Scotland, there has been a distinction between expert and professional witnesses. A common feature is the appointment of an agreed expert to give evidence on aspects of a case that require expert testimony. These changes do not apply in criminal cases nor in other jurisdictions such as the Republic of Ireland. However, all witnesses, whether professional or expert, must be objective, since their role is to assist the court. There is little or no training of clinicians in how to become an expert and suggestions for improving this are discussed. Practical aspects of accepting a brief from a solicitor are considered.

Psychiatrists are frequently called to give evidence in court because they are experts in the field of psychiatric medicine. The situations in which this occurs are varied, ranging from evaluating the psychiatric impact of personal injury to considering retrospectively the testamentary capacity of a deceased person or deciding on the capacity of a person to stand trial (Casey \& Craven, 1999).

\section{The Woolf reforms/Civil Procedure Rules}

The Woolf reforms (Lord Chancellor's Department, 1996) dealt with a number of issues relating to the civil courts in England and Wales (but not Scotland or Northern Ireland) and these have now been incorporated into the judicial system as the Civil Procedure Rules. However, they do not extend to the criminal courts. There are no similar reforms in the Irish Republic although they have been suggested. Comprehensive reviews of Civil Procedure Rules are provided by Rix $(2000 a, b)$. These reforms represent an attempt to speed up the lengthy judicial process, reduce the cost and codify the role of the expert witness. An important element is the appointment, in some cases, of a single expert rather than an expert for each side. Under Civil Procedure Rules, certain requirements regarding the report to the court are also specified, among them a statement confirming that the expert understands his or her duty to the

For Part 2, see pp. 183-190 and for Commentaries, see pp. $187-189$ and $189-190$, this issue. court and that this has been complied with. The expert's report must also contain a declaration prepared in accordance with the Code of Guidance for Experts contained in the Civil Procedure Rules.

\section{Professional $v$. expert witnesses England and Wales}

As early as the 1980s, the distinction between expert and professional witnesses was evident in guidance to doctors. Problems arose, however, once the doctor entered the witness box, when attempts were sometimes made to obtain expert evidence from nonexperts, e.g. a general practitioner being asked to prognosticate on post-traumatic stress disorder. An important element of Civil Procedure Rules has been to make it more difficult to cross the boundary from professional to expert witness when giving testimony.

Independent experts have played a significant role in family law for some years but the establishment of the Civil Procedure Rules in the civil courts was the culmination of a gradual refinement of the role of the expert witness as an independent and impartial advisor to the court. One element of this has been the greater use of the single 'joint expert'. Under Civil Procedure Rules, both parties decide which issues require expert testimony and may agree to engage a joint expert. Sometimes there is a failure to reach such agreement and each side is allowed to appoint its own expert. Occasionally, the court will make an order for the appointment of a single joint expert but it is rare for the court to actually choose who this should be.

Patricia Casey is Professor of Psychiatry at University College Dublin and a consultant psychiatrist at Mater Hospital (Eccles Street, Dublin 7, Ireland). 
Any doctor already treating the patient would then be required to give evidence only as a professional witness and the nature of the evidence would be factual (such as dates of appointments, treatments used), rather than offering an opinion on, for example, aetiology or prognosis. Often this information may be admitted in the form of copies of medical records, without calling the doctor as a witness.

The expert witness, on the other hand, is expected to give a non-partisan opinion and is chosen because of his or her special expertise in an area. The expert will usually have had no prior involvement with the claimant (plaintiff or pursuer) and the opinion will therefore be seen to be truly independent of any therapeutic alliance that may compromise impartiality.

In spite of the concerns about bias, once in the witness box, both professional and expert witnesses are expected to observe the rules of evidence and to assist the jury and judge rather than presenting a partisan perspective on the case.

\section{Republic of Ireland}

In Ireland, the position is significantly different as no distinction is made between the expert and professional witness, at least where consultants giving evidence in their speciality are concerned. If a patient is under the care of a psychiatrist because the consequences of, say, an accident, then that treating doctor becomes the expert witness for that claimant. A doctor treating a patient has no ethical discretion in this case and must provide a report and give evidence if requested to do so. Failure to comply could result in a complaint to the Medical Council of Ireland, as such an action contravenes the specifications in section 9 of its Ethical Guide (Medical Council of Ireland, 1998). Thus, a psychiatrist who is treating the patient will be retained as the expert and the 'other side' will appoint its own expert. However, professionals will consult with each other and exchange reports as a means of identifying areas of disagreement.

When compiling the report for the court and later, when giving evidence about a patient under his or her care, the professional/expert will be expected to be impartial, even when this might not be to the patient's liking. In Ireland, patients involved in personal injury cases are often referred to a psychiatrist by their solicitor exclusively for the purposes of obtaining a medico-legal report. Charges of being a 'hired hand' may be levelled at the psychiatrist and it is therefore highly advisable to seek a psychiatric referral from the general practitioner in the usual manner.

\section{Box 1 Becoming an expert witness}

Observe other experts

Attend pre-trial meetings

Challenge academic case conferences

Undertake specific training courses by expert witness organisations and universities

Prepare medico-legal court reports, under supervision

In criminal and family law cases in Ireland, the approach to expert and professional witnesses is similar to that in England and Wales.

\section{How to become an expert}

Until recently, there was little to assist the psychiatrist-in-training to become an expert witness (Box 1). It is remarkable that during psychiatric training little attention is paid to this area, except for those training in forensic psychiatry. Most psychiatrists have therefore developed these skills through experience and are largely self-taught. The practice of observing other experts giving evidence is neglected, yet it is a simple and effective way of acquiring at least some of the skills and of becoming familiar with court procedures, which themselves can be daunting to the uninitiated. Psychiatrists who have an interest in medico-legal work should also encourage trainees to join them when attending pre-trial meetings or conferences and court hearings. The academic case conference could also be used as preparation for subsequent medico-legal work, particularly when there is incisive and challenging discussion around a case. Doctors-in-training should also be encouraged to prepare medico-legal reports on patients under their care, under the close supervision of the consultant.

Although mentoring is very helpful, doctors-intraining need personal practice at giving evidence and of being cross-examined. There are a number of organisations that provide this training in Britain and Ireland, some of which are listed in Box 2 . These organisations run courses in report writing, general courtroom and cross-examination techniques, handling legal documentation, etc. and, although expensive, they provide very useful training. The law departments of some universities also hold weekend seminars in these topics.

Over the past 10 years, a number of expert witness organisations have evolved that publish codes of practice and produce newsletters and case notes on judgements relevant to the various medical specialities; some of these have a membership examination. There are also two registers of experts 


\section{Box 2 Useful addresses}

Academy of Experts, 2 South Square, Gray's Inn, London WC1R 5HT, UK (Tel: 0207637 0333)

Bond Solon, 13 Britton Street, London EC1M 5SX, UK (Tel: 0207253 7053)

Expert Witness Institute, Africa House, 64-78 Kingsway, London WC2B 6BD (Tel: 0870366 6367; 0207405 5854)

La Touche Bond Solon, The Georgian Business Centre, 20 Lower Baggott Street, Dublin 2, Ireland (Tel: +353 (1) 634 5322)

Law Society Directory of Expert Witnesses, Sweet \& Maxwell, 100 Avenue Road, London NW3 3PF, UK (Tel: 0207393 7000)

Law Society of Ireland, Blackhall Place, Dublin 7, Ireland (Tel: +353 (1) 672 4800)

Law Society of Scotland, 26 Drumsheugh Gardens, Edinburgh EH3 7YR (Tel: 0131226 7411)

Society of Expert Witnesses, PO Box 345, Newmarket, Suffolk CB8 7TU (Tel: 0845702 3014)

UK Register of Expert Witnesses, JS Publications, PO Box 505, Newmarket, Suffolk CB8 7TF (Tel: 01638 561590)

to assist the legal profession - the Law Society Directory of Expert Witnesses and the UK Register of Expert Witnesses. The Law Society of Scotland now also has its own register of experts.

In late 2000, the Home Office established the Council for the Registration of Forensic Practitioners to compile a register of accredited experts in the forensic sciences, but currently its remit covers only those working at the scene of crime and does not yet extend to medical doctors. There is concern, however, that the Council's jurisdiction may in the future extend to all forensic practitioners and that only specifically accredited psychiatrists would be able to give expert evidence, at least in criminal cases.

\section{The instruction}

When an expert is asked to become involved, it is important to be clear about the instruction, i.e. what aspects of the case require expert consideration. The instruction given by the solicitor to the expert will vary and will not necessarily require evaluation of a patient, although this is usually the case. Sometimes, the expert will be asked to comment on a particular report provided by another professional such as a treating psychiatrist or to consider case notes in relation to the management of a patient in a negligence case. On occasions, it may be a general instruction as to whether or not a particular incident such as a traffic accident caused a psychiatric disorder or, if liability is admitted, the issue may be one of the severity of a disorder and of the ensuing incapacity or disability.

\section{What is an expert?}

A well-developed case law now exists in relation to the role and function of an expert in court. These were clearly outlined in the Ikarian Reefer judgement (National Justice Compania Naviera S.A. v. Prudential Assurance Co. Ltd, 1993) and recently expanded in Anglo Group plc, Winther Browne Co. Ltd v. Winter Brown \& Co. Ltd [2000] to conform to the reforms (Lord Chancellor's Department, 1996), with particular reference to the independence of experts.

The following are the requirements of the expert witness (Box 3).

- The expert must be qualified in the field in which expertise is claimed. Thus, an adult psychiatrist would be ill-advised to become involved in a child psychiatry case except perhaps in cases involving the evaluation of a parent's mental stability.

- If the doctor is only to deal with issues within his or her area of expertise, it follows that he or she must be well versed in the issues under consideration, being familiar not just with the statements of the patient but also with current research and best practice in the particular area concerned. Demonstrating that the expert is not versed in current research is one of the techniques used in cross-examination to undermine the evidence given by the expert witness. Modern terminology must be used in the report and when giving evidence. Thus, terms such as 'inadequate personality' or 'neurotic depression' should be avoided.

- The doctor must be non-partisan, even when called to give evidence about a patient he or she is treating. If the doctor has material information that will detract from the claim then this information must be made available.

\section{Box 3 Attributes of the expert}

Qualified in the field

Familiar with current research

Non-partisan

Able to separate fact from opinion

Able to provide a basis for the opinion reached

Must have examined the defendant recently, if relevant 
For instance, if a person claims that a particular road traffic accident caused the present depressive episode and the psychiatrist has information showing that the patient was already depressed at the time of the accident, this must be revealed. The function of a psychiatrist as a hired hand is unacceptable and is contrary to the ethos of the new Civil Procedure Rules. That is not to say that there will be no disagreements between experts, but as long as the opinion is formed in good faith and on the basis of the highest standards of clinical practice, then no ethical difficulties exist.

- As outlined in Davie v. Edinburgh Magistrates (1953), the information imparted must be that which is not ordinarily available to the court, and the expert's duty is 'to furnish the judge and jury with the necessary scientific criteria for testing the accuracy of their conclusions, so as to enable the judge or jury to form their own independent judgement by the application of these criteria to the facts provided in evidence'. Developing this theme, in Rv. Turner [1975], the Honorable Justice Lawton noted that 'Jurors do not need psychiatrists to tell them how ordinary folk who are not suffering from any mental illness are likely to react to the stresses and strains of life'. It follows from these comments that even though the doctor is called as an expert, the court is under no obligation to accept the evidence given.

- The expert must make clear which elements of the report and evidence are based on fact and which are opinion. Thus, comments such as 'the patient had a long history of depression' could mean that the psychiatrist has formed the opinion that the patient has such a history or, alternatively, that the psychiatrist is aware of the fact of such a history from other evidential sources. The mixing of opinion and fact can lead to significant confusion for the court. Both elements are necessary at various stages of the trial and, for this reason, the distinction must be to the fore both in the medico-legal report and when giving evidence.

- The expert must be able to argue the basis for his or her opinion. This means considering alternative explanations and outlining the reasons for the opinion formed. If, having received further information, the expert changes his or her mind, this must be conveyed in writing to those instructing the expert. This requirement forms part of the Expert Declaration that is always signed when the expert is appointed in a civil case in England and Wales. In Ireland, there is much less formality associated with alterations to an opinion but it is assumed than any change will be conveyed to the instructing solicitor. Potentially, an expert who fails to disclose a change of opinion could subsequently be held legally responsible for the failure of the case.

- The expert must have conducted a recent examination of the patient, although in some circumstances this is not required or possible, for example if the role of the expert is to evaluate case notes in challenges to testamentary capacity or certain medical negligence cases.

- If the information on which the report and testimony are based is incomplete, for example owing to the absence of a full history following a stroke, this must be stated both in the report and in evidence.

\section{Setting out the stall}

When asked to become involved in a case, there are a number of preliminary steps that must be taken to avoid embarrassment or uncertainty as to the required role. It is important to confirm that the expert's role is non-partisan, so that when one side appoints the expert there is no certainty that the report will necessarily be favourable. Individuals who request an expert opinion are often not warned of this by their legal team, which can cause significant resentment. Although this might not be so important in a climate where the single joint expert is the norm, it is necessary in the Republic of Ireland, where the adversarial approach continues and where experts are perceived as representing one side or the other.

The expert must also confirm the likely number of visits over which the plaintiff will be evaluated, whether collateral information will be required and whether the general practitioner and other treating doctors will be contacted. The likelihood of a request for a psychologist's or other associated report must also be raised at an early stage during the evaluation since this could delay the case and have an impact on the costs. Increasingly, experts are advised to have a formal contract with the person or agency commissioning the report and model 'contracts' are available from the Academy of Experts and the Expert Witness Institute (Box 2).

In England and Wales, it is common for all relevant medical records to be made available to the expert. In Ireland, this does not always occur and if the expert feels that it is necessary to see in-patient notes, they can be made available or sought through discovery. This request should be made as early as possible since procurement can be a lengthy process. 
Finally, the cost of preparing the report must be discussed, notwithstanding the reluctance of many doctors openly to discuss financial matters. Practices regarding fees vary in each jurisdiction. In England and Wales, fees are not set and must be agreed between the expert and the solicitor. It is rare for these to be discharged in advance of the report being sent, whereas in Ireland this is an almost universal practice, except for those who receive legal aid, when fees are discharged on completion of the case. Moreover, in Ireland, there are agreed rates between the legal profession and doctors' professional bodies and, unless discussed, it is assumed that these rates are acceptable.

The location at which the case will be heard and possible dates of the hearing must be discussed at the outset in order to confirm availability. It might be necessary for the expert witness to attend for all or most of the case, for example if it is a complex one or if each expert must hear the others' evidence; this must also be considered at the beginning of the case.

\section{The court report}

The court report is an important document since it affords the opportunity to present an objective and coherent account of the patient's illness, aetiology and prognosis in the court. A detailed discussion on the preparation of reports is beyond the scope of this paper and the reader is referred to a number of recent papers on this subject (Torr , 1998; Rix, 2000b) and to the organisations listed in Box 2, some of which have developed suitable models.

\section{What evidence can be admitted?}

This is particularly pertinent for psychiatrists, whose main investigative tool is listening and obtaining information from the patient and relatives. Caution must be exercised in relaying information gathered from relatives since they may be biased and since some of the information may constitute hearsay and be inadmissible as evidence. In criminal cases, such information may also raise issues regarding third-party confidentiality.

However, in civil cases, not to have interviewed an informant in order to evaluate the impact of a particular event might be considered to constitute less than optimal practice, as collateral information is an important element in arriving at a diagnosis and formulation in day-to-day clinical practice. If the expert's conclusion takes account of this lacuna, however, it might not be challenged in the witness box. If assessment of personality is a key element of the case, as in civil annulment cases, obtaining collateral information is essential. In general, only information given about directly observed aspects should be included. For example, if a patient told the informant that he was sleeping badly and this was conveyed to the doctor, it would be hearsay. However, if the informant observed the patient awake during the night, this would not be hearsay and could be included.

Sometimes, a judge will refuse to admit evidence relating to evaluations of the patient carried out by other members of the multi-disciplinary team, on the basis that it constitutes hearsay. Generally, however, most judges and counsel accept as valid information gathered by all the mental health professionals who are part of the expert's / professional witness's team that is dealing with the plaintiff. Information gleaned from so-called memoryenhancing techniques, such as hypnosis and abreaction, is not admissible owing to uncertainty about its accuracy.

Sometimes, the expert may be directed by the judge to base the diagnosis on the symptoms, as reported under examination in the witness box, rather than on those provided at the medico-legal consultation. This will require the expert to hear all the evidence, make notes and prompt counsel to enquire about specific symptoms during the direct examination and cross-examination of other witnesses. If the expert is unable to be present during testimony, then a transcript of the evidence must be obtained before he or she enters the witness box.

Only evidence that is relevant to the case is admitted. If, following a road traffic accident, the defence accepts that the plaintiff suffered posttraumatic stress disorder, the question of whether the accident caused the symptoms becomes irrelevant and the issue becomes one of severity instead.

Finally, the court is under no obligation to accept any evidence of experts or professional witnesses that it considers to be based on information available to the person on the street (Davie v. Edinburgh Magistrates, 1953).

\section{Pre-trial meeting/conference with counsel}

The pre-trial meeting or conference is important as it will allow both counsel and expert to examine the reports in detail. During this meeting, it is important to inform the legal team if there has been a change of opinion after consideration of further information that has come to light since the initial report (even though in the UK (excluding Scotland) any changes of opinion must have been conveyed in writing to the instructing legal team). Changes of opinion may determine the strategy in the case or even whether to proceed with it or not. 
If two experts have been appointed, the likely line of cross-examination can be discussed. Counsel should also be alerted to any weaknesses that the expert sees in the case from his or her perspective, and knowledge and guidance must be provided to counsel in relation to areas that require clarification during the trial or during cross-examination of the expert representing the other side. Up-to-date research that may be relevant to the case should also be made available at this meeting.

\section{References}

Casey, P. \& Craven, K. (1999) Psychiatry and the Law. Dublin: Oak Tree Press.

Lord Chancellor's Department (1996) Access to Justice: Final Report to the Lord Chancellor on the Civil Justice System in England and Wales (Woolf Report). London: Stationery Office.

Medical Council of Ireland (1998) A Guide to Ethical Conduct and Behaviour (5th edn). Dublin: Medical Council of Ireland.

Rix, K. J. B. (2000a) The new Civil Procedure Rules. 1. The process of dispute resolution and litigation. Advances in Psychiatric Treatment, 6, 153-158.

- (2000b) The new Civil Procedure Rules. 2. Part 35 provisions and their implications. Advances in Psychiatric Treatment, 6, 219-225.

Torr, J. (1998) The model form of medical expert's report. Expert, (Autumn), 24.

Anglo Group plc, Winther Brown \& Co. Ltd v. Winter Brown E Co. Ltd. [2000] England and Wales High Court (Technology and Construction Court) Decisions. March.

Davie v. Edinburgh Magistrates [1953] SC 34.

National Justice Compania Naviera S.A. v. Prudential Assurance Co. Ltd. (Ikarian Reefer Case) [1993] 37 EG 158.

$R$ v. Turner [1975] QB 834; 60 Cr App R 80.

\section{Multiple choice questions}

\section{The expert:}

a must always represent the best interests of the patient

b must always provide objective information to the court

c must always argue the case against the defence

$\mathrm{d}$ must never concede, even in the face of evidence to the contrary

e must have practical rather than academic knowledge of the subject matter under consideration.
2 The expert:

a should inform the legal team if he or she has any change of mind in relation to any matter of substance in the court report

b should update the legal team on the current state of knowledge in the area before the trial

c must provide an explanation for the opinion that has been reached

d should avoid academic discussion during evidence

e must uphold his or her patient's case.

3 The expert:

a can expect that evidence given will be accepted by virtue of his or her expertise

$\mathrm{b}$ is allowed to invoke hearsay

c may have his or her expertise challenged in court

d can offer an opinion only if he or she has seen the patient for examination

e should always bolster his or her opinion with standardised measures.

4 The Woolf reforms:

a have eliminated the need for expert witnesses

$\mathrm{b}$ have codified the role of the expert witness

c have extended the adversarial nature of expert testimony

d apply to criminal cases only

e have led increasingly to the appointment of an agreed single joint expert.

\section{MCQ answers}

$\begin{array}{lllll}\text { 1 } & & 2 & 3 & 4 \\ \text { a F } & \text { a T } & \text { a F } & \text { a F } \\ \text { b T } & \text { b T } & \text { b F } & \text { b T } \\ \text { c F } & \text { c T } & \text { c T } & \text { c F } \\ \text { d F } & \text { d F } & \text { d F } & \text { d F } \\ \text { e F } & \text { e F } & \text { e F } & \text { e T }\end{array}$

